\title{
Appropriate and necessary oral care for people with cancer: guidance to obtain the right oral and dental care at the right time
}

\author{
Joel B. Epstein • Pelin Güneri • Andrei Barasch
}

Received: 23 December 2013 / Accepted: 21 March 2014 / Published online: 28 March 2014

(C) Springer-Verlag Berlin Heidelberg 2014

\begin{abstract}
Purpose The identification of experienced and knowledgeable dental specialists to provide appropriate oral care for cancer patients, as well as the integration of this care within general oncology management, may be a challenge. This paper discusses the general and additional requirements for dental care providers to support the cancer patient and provide prevention and/or treatment for oral complications of cancer therapy.

Methods We performed a literature review of specific issues regarding the oral cavity and adjacent structures in the cancer patient, including detection and early diagnosis of oral malignancy. We incorporated the systemic effects of cancer and its therapy that affect oral disease and treatment. We present a summary of how to seek expert dental care for cancer patients and for referral from the dental and medical community. Results Due to the complexity conferred by the disease and its treatment, cancer patients require educated, experienced dentists for treatment and/or prevention of oral-related morbidity. Correct diagnosis and evidence-based prophylactic and
\end{abstract}

J. B. Epstein

Samuel Oschin Comprehensive Cancer Institute, Cedars-Sinai

Medical Center, Los Angeles, CA, USA

J. B. Epstein

Division of Otolaryngology and Head and Neck Surgery City of Hope National Medical Center, Duarte CA, 8500 Whilshire Blvd, Suite 800, Beverly Hills, CA 90211, USA

P. Güneri $(\bowtie)$

Department of Oral and Maxillofacial Radiology, Ege University

School of Dentistry, Bornova 35100, İzmir, Turkey

e-mail: peleen_2000@yahoo.com

A. Barasch

Department of Dental Medicine, Winthrop-University Hospital, 259

First Street, Mineola, NY 11501, USA therapeutic oral care can significantly improve patient quality of life and reduce morbidity and healthcare costs.

Conclusions The knowledge and expertise of dental professionals regarding prevention/treatment of complications and secondary malignant lesions in cancer patients are critical. Integration of oral care with the oncology care and in survivors requires effective communication between dental and medical providers beginning ideally at diagnosis. These clinicians may be identified at the cancer center, nearby hospital dental programs, and, less commonly, in the community.

Keywords Cancer treatment protocol · Oral mucositis · Oral mucosa $\cdot$ Oral manifestations $\cdot$ Second neoplasms

\section{Introduction}

Increasing numbers of survivors of cancer and of people living with cancer present new clinical challenges and increase the need for collaboration between physicians and dental professionals. Advances in cancer treatment include intensitymodulated radiotherapy (IMRT), image-guided radiotherapy (IGRT), ARC therapy, proton therapy, surgical technique (e.g., laser, robotic surgery, implants, vascularized tissue transfer), dose-dense chemotherapy regimens, targeted agents, immunotherapy, and maintenance therapy. These advances have led to improved cure rates, increased survivorship, and a growing number of people living with cancer [1-3].

Dental care for these populations represents a clinical challenge, which mandates collaboration between physicians and dental professionals. Many community dental practitioners are not ideally prepared to provide treatment to this medically complex type of patient. Dental specialists with sufficient training and experience should be sought in order to provide appropriate, safe, and effective oral care for these patients. Similarly, patient education regarding potential oral side 
effects, their prevention and/or amelioration, as well as necessary prophylactic information is an integral part of the oral and systemic care for these patients.

General considerations in cancer therapy and impact on oral condition

Patients with head and neck cancers may be treated with surgical resection, external beam radiotherapy and/or brachytherapy, and systemic drugs (chemotherapy and/or targeted agents), depending on the location, stage, and histology of the tumor and the clinical condition of each patient $[2,4]$. Treatments may be provided as single modality for early stage, localized disease, or more commonly, due to late stage diagnosis, using combined modalities of care [2, 5-7].

People with cancers of the hematopoietic system typically receive myelosuppressive and immunosuppressive therapy that may include hematopoietic stem cell transplants (HSCT). These patients present additional complex care needs due to both the primary cancer and the medical complexities during survivorship, potentially with high risk of multiple oral/dental problems and therapy-related oral complications. Oral/dental care before, during, and following cancer therapy requires coordination with the medical providers, as oral disease may affect the timing and efficacy of cancer therapy and, conversely, cancer therapy may affect the feasibility and outcomes of dental treatment [2, 5, 7-18].

Cycled chemotherapy with or without targeted therapies for patients with non-oral solid tumors may also lead to oral complications. For these patients as well, dental care must be delivered in the setting of the underlying medical condition [2].

\section{Oral complications of cancer therapy}

Oral compromise during cancer therapy, including mucositis, infection, hyposalivation, taste change, and pain, can be significant $[5,7,9]$. These side effects and toxicities can alter all aspects of oral and oropharyngeal functions affecting diet (taste, dry mouth, chewing, and swallowing) and therefore nutrition. Furthermore, speech, ability to maintain oral hygiene, wearing dental prostheses, and appearance may negatively influence oral health, social, and emotional wellness [2, 19-22]. These side effects may also affect the ability to deliver cancer therapy as planned and thus, systemic health, outcomes of cancer therapy, and the cost of care [2, 5, 9, 20, 22-40].

The above-mentioned oral and dental effects of cancer therapy are mostly acute conditions. Additional chronic complications include risk of necrosis of soft and hard tissues (osteoradionecrosis and osteonecrosis risk with osteolytic inhibitors (e.g., bisphosphonates and denosumab)) [25, 41], dental caries [25], disruptions in dental growth and development [42], graft vs. host disease (GVHD) in HSCT patients
[43, 44], fibrosis/trismus (limited movement of soft tissue including lips, tongue, neck, jaw, as well as esophageal stricture and motility), dysgeusia, dysphagia, salivary gland dysfunction, and chronic pain (neuropathic, temporomandibular disorders, dental, and periodontal) $[1,2,9,20,21,23-25,28$, $31,33,34,37-39,45-53]$. The impact of these conditions upon oral and systemic health and general well-being is significant.

\section{Oral care principles}

Prevention of these oral complications, early recognition, diagnosis, and management often bridge expertise in both medical and dental cares. With timely and effective care of acute oral complications, completion of planned cancer treatment protocols can be supported for best outcomes, including improved cure rates [5, 14, 22, 24, 27, 29]. Unfortunately, cancer patients often have suboptimal oral health prior to cancer diagnosis $[9,54-56]$ and, therefore, are at increased risk for odontogenic (potentially life-threatening) infections during cytotoxic therapy. They may also have an increased risk for mucositis $[9,5,55]$.

\section{Cancer survivors}

Following cancer therapy, most survivors experience life-long risk for oral and dental disease: for example, any traumatic incident or oral infection originating from periapical and periodontal foci may cause bone necrosis after radiotherapy, with a similar risk for patients on prolonged osteolytic inhibitor therapy for bone metastases of cancer [2, 5, 7, 38, 57]. Hence, pretreatment dental assessment is critical and in some cases is the only opportunity for management of preexisting dental conditions that may lead to significant and difficult to manage complications during and/or following cancer treatment [2, 5, $23,54-56,58]$.

The needs of patients following cancer therapy may be best addressed by appropriate treatment prior to initiation of cancer remedies and with active dental prevention in place [38, 47]. Therefore, as suggested by the British Association of Head and Neck Oncologists, all cancer patients should be assessed by "a suitably qualified dental practitioner" before and after their main treatment [59], and integrated multidisciplinary health care teams including dental expertise must be the initial step to provide optimum treatment for cancer patients [5, $7-11,13-17,47]$. As stated by the International Society of Oral Oncology, "an accurate knowledge of the burden of illness, effective prevention, and treatment of oral complications associated with cancer therapies is necessary for management of the numerous oral complications of cancer therapy." (http://www.mascc.org/assets/documents/Oral_CareSummary-Oral_Complications_Systematic_Reviews.pdf., Accessed on 02.11.2013). 
Clearly, early planning and coordination between the dentist and the oncology team must occur, so that appropriate oral care can be provided at the appropriate time. Additionally, urgent and emergent dental needs may be managed when the patient is best able to tolerate the treatment, provided at a time of lowest risk to the patient or with appropriate medical support, to facilitate best outcomes which may reduce the need for additional hospitalization and intensive medical care that may impact survival and increase economic burden of treatment $[9,18,19,28,60,61]$. Therefore, oral and dental care before, during, and following cancer therapy are an important part of cancer treatment [7] and are best provided by educated and experienced dental providers, with good communication with the oncology team [47].

Sequence of oral care prior to, during, and following cancer therapy

The role of the dental provider in the integral care of the oncology patient consists of ongoing involvement from disease diagnosis through survivorship. Oral care of oncology patients should begin soon after diagnosis, with recognition of local-regional conditions including potentially malignant oral disease and oral findings of systemic cancers that may present with local signs and/or symptoms [2]. It continues with dental examination/diagnosis and management of common oral diseases in preparation for cancer therapy and prevention and management of oral complications during treatment and survivorship [2, 7, 10, 23]. Follow-up of the patient during cancer therapy is dependent on the type of therapy and potential oral effects. Head and neck cancer and hematological malignancy patients should be consulted at least weekly, while other solid tumor patients may be followed on an as needed basis.

Oral care in survivorship is also based on the specific disease and patient's oral condition. Generally, close followup is indicated for detection of recurrence or second malignancy. Frequent dental recalls should also be in order, particularly for patients with hyposalivation and/or immune compromise. This continuing involvement contributes to patient oral comfort and potential avoidance of inherent oral complications but may allow completion of planned cancer therapy affecting outcome of cancer treatment and long-term general outcomes.

It is essential that an informed and experienced dentist who is familiar with oro-dental needs of cancer patients and has an understanding of the impact cancer and cancer therapy may have upon dental treatment be part of the oncology team or at least be consulted $[2,62]$. Integrated oncology teams have been suggested to provide the complex range of services across the cancer continuum. Also, supportive care services, such as education, psychosocial support, speech therapy, nutritional counseling, genetic counseling, or other types of supportive care should be provided [7, 10].
Oral/dental health care is clearly more complex in these patients and requires experienced providers and integration with the medical care $[56,59]$. Considering onset, duration, and nature of the cancer therapy, and the patients' oral and dental needs, dental treatment should be planned at the time of cancer diagnosis and before initiation of therapy (Table 1) $[1$, $2,4,7,9,23,56,60,63,64]$. This plan should include oral hygiene instruction, as well as necessary dental and/or surgical interventions to minimize imminent risk of infection and pain and to address future risk of dental disease.

Pretreatment oral/dental care must also include preventive strategies directed to the specific oral and dental condition and the cancer and systemic status of the patient $[2,7,63]$. Since dental needs of each patient are unique, and treatment modalities for medically compromised patients should be planned individually for every person, this dental program must be based upon the patient's oral and dental status, previous dental care, and periodontal tissues' condition, cancer diagnosis, comorbid medical conditions, planned cancer therapy, knowledge of oral complications of therapy and prognosis, and maxillofacial/prosthetic rehabilitation of the cancer-related areas and defects $[2,5,9,23,28,29,60]$. This extensive background requires specific dental education that is not part of the typical dental school curriculum and is often beyond the training and experience of the community dental practitioners.

In addition to prevention and proper management of oral complications of cancer therapy, detection of signs, and diagnosis of recurrent oral cancer in the same area, or second and/or metastatic cancer in previously treated people, also requires extensive training and experience [2, 17, 65-67]. Patients with previous cancer in the upper aerodigestive tract have the potential to develop local recurrences or second primary tumors $[1,68,69]$. When a suspicious condition is observed, the need to achieve diagnosis and the implications of the results should be discussed with the patients in order to promote understanding and compliance [70]. Oral squamous cell carcinoma (OSCC) patients require a dentist to discuss their oral health/teeth, chewing/eating, pain in head and neck, saliva, swallowing, and speech as their major concerns [11, 71]. This is also important in terms of dental maintenance, because an appropriate dental care plan shall be constructed on individual patient basis with careful analysis of the risks and the benefits of dental intervention [7].

\section{Providers of oral care for cancer patients}

The cancer team and the dental provider require the expertise to initiate the prevention and management of the oral complications prior to, during, and following cancer therapy $[2,7,20$, $23,45,54,63,64$,] and, also, have a mandate for early detection of new or recurrent cancer in the head and neck 
Table 1 An ideal design for a model dental strategy prior to cancer therapy [1, 23]

\begin{tabular}{|c|c|}
\hline \multicolumn{2}{|l|}{ Oral assessment of cancer patients } \\
\hline Preradiation treatment & Prechemotherapy treatment \\
\hline Definitive diagnosis & Definitive diagnosis \\
\hline Medical history and current medical status & Medical history, systemic status (CBC etc.) \\
\hline Dental history/past dental care/dental hygiene status & Dental history/past dental care/dental hygiene status \\
\hline $\begin{array}{l}\text { Complete dental exam (e.g., mucosal dental exam, periodontal, } \\
\text { temporomandibular joint) }\end{array}$ & $\begin{array}{l}\text { Complete dental exam (e.g., mucosa, dental exam, periodontal, with } \\
\text { focus on sites of symptomatic infection) }\end{array}$ \\
\hline $\begin{array}{l}\text { Radiographic survey (panoramic and adjunctive periapicals or full- } \\
\text { mouth periapicals) }\end{array}$ & Adjunctive tests as indicated (e.g., dental imaging, pulp tests, cultures) \\
\hline Saliva tests (unstimulated and stimulated saliva volumes) & Prognosis for cure vs. palliation \\
\hline Assessment of mouth opening before radiotherapy & $\begin{array}{l}\text { Planned treatment/date of treatment (should be finished at least } 10 \text { days } \\
\text { before initiation of cancer therapy) }\end{array}$ \\
\hline \multicolumn{2}{|l|}{$\begin{array}{l}\text { Adjunctive tests as indicated (e.g., pulp tests, cultures, range of jaw } \\
\text { opening, saliva volume) }\end{array}$} \\
\hline \multicolumn{2}{|l|}{ Prognosis for cure vs. palliation } \\
\hline $\begin{array}{l}\text { Proposed treatment (radiation dose/number of fractions)/date of } \\
\text { treatment and radiation fields/chemotherapy, transplant }\end{array}$ & \\
\hline
\end{tabular}

and oral environment. Currently, few cancer centers have experienced dental practitioners integrated in the cancer team and available to provide appropriate oral care prior to, and throughout cancer continuum; and even fewer have integrated dental treatment services on site [7, 24, 28, 47, 72]. Some centers have consultants and some have no organized or experienced dental providers to call upon for best care [72].

Another major obstacle is funding for dental services, which can be a challenge in the oncology community. One can look at these integrated services as "medically necessary," but the limited community base of knowledge is also challenging $[47,56]$. If these patients fail to receive the appropriate care, they have an increased risk of dental problems during or after cancer treatment and oral complications in the cancer continuum, which results in economic and health burden [56].

In a large study, only $35 \%$ of oral cancer patients had a regular dentist and dental care [67] and about $22.7 \%$ of cancer care centers for pediatric patients have a nurse in the oncology team who is responsible for oral care issues [42]. Even though an experienced dentist who can work as a consultant to coordinate the dental care of patients by liaison with primary care dental practitioners is essential, dental assessment is recorded in only $8.5 \%$ of the 6,458 patient registrations (551 patients) and $12.8 \%$ of the 4,297 of patients with treatment plans [73].

\section{Current conditions}

In community practice, many dental care providers are not prepared to manage oral complications of cancer patients based upon limited undergraduate training (and often even graduate training), limited continuing education, and limited experience in managing medically complex patients, all resulting in a lack of experience in this complex healthcare field [14, 64, 67, 74]. The level of knowledge of dental professionals regarding prevention of common, anticipated complications in cancer patients is also critical, because previously treated cancer patients may have unusual presentation and course of oral conditions, which makes the recognition, diagnosis, and management of such complications challenging. Undergraduate dental curricular demands paired with the lack of general access of most dental schools to this type of complex patients account for the difficulties for the necessary experience to be obtained through undergraduate education. Hence, special postgraduate programs are the only viable alternative for dental practitioners to gain exposure and knowledge in this relatively underserved area of oral care.

In a survey of general dental patients regarding selection of dental providers, key features reported by patients were competence $(90 \%)[75,76]$ and reputation of the dentist $(70 \%)$ [76]. The identification of specifically trained dentists in the setting of cancer care requires increased attention to provider training and experience [73]. Expertise may be available at the cancer center, nearby hospital dental programs, university, and, less commonly, in the community. These experienced providers can be identified by noting training, experience, academic, and research activity. The care can be delivered or guidance can be provided to less-experienced community dentists to ensure appropriate oral care at the right time in the cancer continuum. Increased training of dental professionals in oncology can be embedded in residency/graduate programs and hospital services to increase patient care resources 
Table 2 Guidelines for the patients and providers in seeking expert care for cancer patients and for referral from the dental and medical community

Steps to ensure appropriate oral care in cancer patients and survivors

Insure that prevention of uncommon oral complications are integrated with cancer therapy

Insure that oral care is provided by a dentist familiar with cancer therapies and their expected effects

Provide dental team with information and material detailing expected side effects and physiologic changes, both oral and systemic

Educate patient in mouth and dental issues of concern [11]

Follow-up to include more frequent visits for dental needs and potential early detection of recurrent/new primary tumor [11]

Educate community dental provider that oral/dental treatment may require referral

Special/persisting/unusual conditions may require referral

Oral care must be integrated with medical management in all cancer treatment modalities, especially in HSCT [2]

Information your dentist should request past medical history if treated with radiation therapy: radiation fields/volume treated, past and current chemotherapy; current medical status including relevant medical laboratory results $[2,64]$ medications including bone health medications, chemotherapy and immunosuppressives

Multidisciplinary team and high level expertise may be required in complex cases $[2,21,64,73$,

Advice accessing informed expert dental/oral care in cancer patients and survivors

Cancer center on site providers or list of expert community providers

Inquire at tumor support groups/web sites, prior dentist

Consider oral evaluation and treatment planning by experienced/integrated provider to guide community providers if special care not required. Insure invasive procedures are discussed with cancer center team.

Community dentists should obtain information from cancer center or dentists experienced in oral care of oncology patients

Unique services and expertise may be needed such as: imaging, saliva study, microbial study, cell sampling, biopsy

Referral for unique/unusual findings to experienced dental provider

Unique dental/oral therapy available at some cancer/transplant centers
How to evaluate dental expert provider

Knowledge of cancer diagnosis, cancer treatment, and implications for oral care

Previous experience and ongoing experience with oncology care

Training (residencies, graduate programs, specifically hospital experience)

Current hospital appointments, specifically oncology appointments

Leading experts will have publications in oral oncology (evaluate by search of the dentist on: Pubmed.com, Google Search, Google Scholar)

Continuing education presented (reflects recognized expertise in education by professional communities)

Membership in related societies (e.g., dental oncology, medical oncology groups)

Continuing education attendance/study clubs/ national and international meetings

Web sites of provider

[11]. In some countries, hospital dental training and oral medicine training may include experience in oncology that results in increased expertise in the management of these complex care patients (Table 2).

\section{Conclusion}

Knowledge, experience, interaction, and, ideally, integration with the oncology team provide the assurance of best appropriate oral and dental care for cancer patients. Given the complexities of oral and dental care that may be unique in oncology, the need to understand the cancer diagnosis and stage, the treatment provided or planned, the prognosis of cancer treatment, the complications of therapy and the impact of the medical issues that continue following cancer therapy, and the identification of experienced and knowledgeable dental providers in the community may be a challenge [59, 73]. The financial difficulties are also significant, even when dental insurance is available, due to the extensive and complex needs and even more challenging when dental insurance is limited or not available $[62,71]$. The definition of "medically necessary oral/dental care" and other means of funding the costs of care are not well defined. These issues become of greater 
importance with increased survival, ongoing cancer treatment (control of cancer, maintenance therapy), and continuing advances in cancer care [2].

\section{Conflict of interest None}

\section{References}

1. Hancock PJ, Epstein JB, Sadler GR (2003) Oral and dental management related to radiation therapy for head and neck cancer. J Can Dent Assoc 69:585-590

2. Epstein JB, Thariat J, Bensadoun RJ, Barasch A, Murphy BA, Kolnick L, Popplewell L, Maghami E (2012) Oral complications of cancer and cancer therapy: from cancer treatment to survivorship. CA Cancer J Clin 62:400-422

3. Siegel R, Naishadham D, Jemal A (2012) Cancer statistics, 2012. CA Cancer J Clin 62:10-29

4. Bueno AC, Ferreira RC, Barbosa FI, Jham BC, Magalhães CS, Moreira AN (2013) Periodontal care in patients undergoing radiotherapy for head and neck cancer. Support Care Cancer 21:969-975

5. Hong CH, Napeñas JJ, Hodgson BD, Stokman MA, MathersStauffer V, Elting LS, Spijkervet FK, Brennan MT, Dental Disease Section, Oral Care Study Group, Multi-National Association of Supportive Care in Cancer (MASCC)/International Society of Oral Oncology (ISOO) (2010) A systematic review of dental disease in patients undergoing cancer therapy. Support Care Cancer 18:10071021

6. Huang SH, O’Sullivan B (2013) Oral cancer: current role of radiotherapy and chemotherapy. Med Oral Patol Oral Cir Bucal 18(2): e233-e240

7. Ray-Chaudhuri A, Shah K, Porter RJ (2013) The oral management of patients who have received radiotherapy to the head and neck region. Br Dent J 14:387-393

8. Epstein JB, Robertson M, Emerton S, Phillips N, Stevenson-Moore P (2001) Quality of life and oral function in patients treated with radiation therapy for head and neck cancer. Head Neck 23:389-398

9. Djuric M, Hillier-Kolarov V, Belic A, Jankovic L (2006) Mucositis prevention by improved dental care in acute leukemia patients. Support Care Cancer 14:137-146

10. Brouwers M, Crawford J, Elison P, Evans WK, Gagliardi A, Holmes D, Lacourciere J, Lo D, Mai V, McNair S, Minuk T, Oliver TK, Rabeneck L, Rand C, Ross J, Smylie J, Srigley J, Stern H, Trudeau M (2007) Organizational standards for diagnostic assessment programs. Toronto (ON): Cancer Care Ontario [In review 2011]. Program in Evidence-based Care Evidence-based Series Organizational Standards for DAP IN REVIEW

11. Rogers SN, El-Sheikha J, Lowe D (2009) The development of a patients concerns inventory (PCI) to help reveal patients concerns in the head and neck clinic. Oral Oncol 45:555-561

12. Soga Y, Sugiura Y, Takahashi K, Nishimoto H, Maeda Y, Tanimoto M, Takashiba S (2010) Progress of oral care and reduction of oral mucositis - a pilot study in a hematopoietic stem cell transplantation ward. Support Care Cancer 19:303-307

13. Jones DL, Rankin KV (2012) Management of the oral sequelae of cancer therapy. Tex Dent J 129:461-468

14. Patel Y, Bahlhorn H, Zafar S, Zwetchkenbaum S, Eisbruch A, Murdoch-Kinch CA (2012) Survey of Michigan dentists and radiation oncologists on oral care of patients undergoing head and neck radiation therapy. J Mich Dent Assoc 94:34-45
15. Vijay Kumar KV, Suresan V (2012) Knowledge, attitude and screening practices of general dentists concerning oral cancer in Bangalore city. Indian J Cancer 49:33-38

16. Funk CS, Warmling CM, Baldisserotto J (2013) A randomized clinical trial to evaluate the impact of a dental care program in the quality of life of head and neck cancer patients. Clin Oral Investig PMID: 23989505

17. Ho MW, Field EA, Field JK, Risk JM, Rajlawat BP, Rogers SN, Steele JC, Triantafyllou A, Woolgar JA, Lowe D, Shaw RJ (2013) Outcomes of oral squamous cell carcinoma arising from oral epithelial dysplasia: rationale for monitoring premalignant oral lesions in a multidisciplinary clinic. Br J Oral Maxillofac Surg 51:594-599

18. Kashiwazaki H, Matsushita T, Sugita J, Shigematsu A, Kasashi K, Yamazaki Y, Kanehira T, Yamamoto S, Kondo T, Endo T, Tanaka J, Hashino S, Nishio M, Imamura M, Kitagawa Y, Inoue N (2012) Professional oral health care reduces oral mucositis and febrile neutropenia in patients treated with allogeneic bone marrow transplantation. Support Care Cancer 20:367-373

19. Bellm LA, Epstein JB, Rose-Ped A, Martin P, Fuchs HJ (2000) Patient reports of complications of bone marrow transplantation. Support Care Cancer 8:33-39

20. Citak E, Tulek Z (2013) Longitudinal quality of life in Turkish patients with head and neck cancer undergoing radiotherapy. Support Care Cancer 21:2171-2183

21. Turner L, Mupparapu M, Akintoye SO (2013) Review of the complications associated with treatment of oropharyngeal cancer: a guide for the dental practitioner. Quintessence Int 44:267-279

22. Gautam AP, Fernandes DJ, Vidyasagar MS, Maiya AG, Nigudgi S (2013) Effect of low-level laser therapy on patient reported measures of oral mucositis and quality of life in head and neck cancer patients receiving chemoradiotherapy - a randomized controlled trial. Support Care Cancer 21:1421-1428

23. Epstein JB, Stevenson-Moore P (2001) Periodontal disease and periodontal management in patients with cancer. Oral Oncol 37:613-619

24. Barker GJ, Epstein JB, Williams KB, Gorsky M, Raber-Durlacher JE (2005) Current practice and knowledge of oral care for cancer patients: a survey of supportive health care providers. Support Care Cancer 13:32-41

25. Springer IN, Niehoff $P$, Warnke PH, Böcek G, Kovács G, Suhr M, Wiltfang J, Açil Y (2005) Radiation caries-radiogenic destruction of dental collagen. Oral Oncol 41:723-728

26. Nguyen NP, Moltz CC, Frank C, Vos P, Smith HJ, Karlsson U, Nguyen LM, Rose S, Dutta S, Sallah S (2006) Evolution of chronic dysphagia following treatment for head and neck cancer. Oral Oncol 42:374-380

27. Ben-David MA, Diamante M, Radawski JD, Vineberg KA, Stroup C, Murdoch-Kinch CA, Zwetchkenbaum SR, Eisbruch A (2007) Lack of osteoradionecrosis of the mandible after intensity-modulated radiotherapy for head and neck cancer: likely contributions of both dental care and improved dose distributions. Int J Radiat Oncol Biol Phys 68:396-402

28. Epstein JB, Parker IR, Epstein MS, Gupta A, Kutis S, Witkowski DM (2007) A survey of National Cancer Institute-designated comprehensive cancer centers' oral health supportive care practices and resources in the USA. Support Care Cancer 15:357-362

29. Keefe DM, Schubert MM, Elting LS, Sonis ST, Epstein JB, RaberDurlacher JE, Migliorati CA, McGuire DB, Hutchins RD, Peterson DE (2007) Mucositis Study Section of the Multinational Association of Supportive Care in Cancer and the International Society for Oral Oncology Updated clinical practice guidelines for the prevention and treatment of mucositis. Cancer 1:820-831

30. Boroumand S, Garcia AI, Selwitz RH, Goodman HS (2008) Knowledge and opinions regarding oral cancer among Maryland dental students. J Cancer Educ 23:85-91

31. Porter SR, Fedele S, Habbab KM (2010) Xerostomia in head and neck malignancy. Oral Oncol 46:460-463 
32. Rogers SN (2010) Quality of life perspectives in patients with oral cancer. Oral Oncol 46:445-447

33. Barasch A, Epstein JB (2011) Management of cancer therapy induced oral mucositis. Dermatol Ther 24:424-431

34. Bensadoun RJ, Patton LL, Lalla RV, Epstein JB (2011) Oropharyngeal candidiasis in head and neck cancer patients treated with radiation: update 2011. Support Care Cancer 19:737-744

35. Jager-Wittenaar H, Dijkstra PU, Vissink A, van Oort RP, van der Laan BF, Roodenburg JL (2011) Malnutrition in patients treated for oral or oropharyngeal cancer - prevalence and relationship with oral symptoms: an explorative study. Support Care Cancer 19:1675-1683

36. Mosel DD, Bauer RL, Lynch DP, Hwang ST (2011) Oral complications in the treatment of cancer patients. Oral Dis 17:550-559

37. Watters AL, Epstein JB, Agulnik M (2011) Oral complications of targeted cancer therapies: a narrative literature review. Oral Oncol 47: $441-448$

38. Kühl S, Walter C, Acham S, Pfeffer R, Lambrecht JT (2012) Bisphosphonate-related osteonecrosis of the jaws - a review. Oral Oncol 48:938-947

39. Lyons AJ, Crichton S, Pezier T (2013) Trismus following radiotherapy to the head and neck is likely to have distinct genotype dependent cause. Oral Oncol 49:932-936

40. Nicolatou-Galitis O, Sarri T, Bowen J, Di Palma M, Kouloulias VE, Niscola P, Riesenbeck D, Stokman M, Tissing W, Yeoh E, Elad S, Lalla RV, For The Mucositis Study Group of the Multinational Association of Supportive Care in Cancer/ International Society of Oral Oncology (MASCC/ISOO) (2013) Systematic review of amifostine for the management of oralmucositis in cancer patients. Support Care Cancer 21:357-364

41. Kuchuk I, Mazzarello S, Butterfield K, Appleton A, Addison CL, Clemons M (2013) Oral care and the use of bone-targeted agents in patients with metastatic cancers: a practical guide for dental surgeons and oncologists. J Bone Oncol 2:38-46

42. Glenny AM, Gibson F, Auld E, Coulson S, Clarkson JE, Craig JV, Eden OB, Worthington HV, Pizer B, UKCCSG-PONF Mouth Care Group (2004) A survey of current practice with regard to oral care for children being treated for cancer. Eur J Cancer 40:1217-1224

43. Epstein JB, Nantel S, Sheoltch SM (2000) Topical azathioprine in the combined treatment of chronic oral graft-versus-host disease. Bone Marrow Transplant 25:683-687

44. Stoopler ET (2013) Management of oral chronic graft-versus-host disease. J Can Dent Assoc 79:d37

45. Mealey BL, Semba SE, Hallmon WW (1994) The head and neck radiotheraphy patient: Part 2-management of oral complications. Compendium 15:442, 444, 446-452, passim; quiz 458

46. Andrews N, Griffiths C (2001) Dental complications of head and neck radiotherapy: part 1 . Aust Dent J 46:88-94

47. McGuire DB (2003) Barriers and strategies in implementation of oral care standards for cancer patients. Support Care Cancer 11:435-441

48. Louise Kent M, Brennan MT, Noll JL, Fox PC, Burri SH, Hunter JC, Lockhart PB (2008) Radiation-induced trismus in head and neck cancer patients. Support Care Cancer 16:305-309

49. Brennan MT, Elting LS, Spijkervet FK (2010) Systematic reviews of oral complications from cancer therapies, Oral Care Study Group, MASCC/ISOO: methodology and quality of the literature. Support Care Cancer 18:979-984

50. Nicolatou-Galitis O, Kouloulias V, Sotiropoulou-Lountou A, Dardoufas K, Polychronopoulou A, Athanassiadou P, Kolitsi G, Kouvaris J (2011) Oral mucositis, pain and xerostomia in 135 head and neck cancer patients receiving radiotherapy with or without chemotherapy. Open Cancer J 4:7-17

51. Cooperstein E, Gilbert J, Epstein JB, Dietrich MS, Bond SM, Ridner SH, Wells N, Cmelak A, Murphy BA (2012) Vanderbilt head and neck symptom survey version 2.0: report of the development and initial testing of a subscale for assessment of oral health. Head Neck 34:797-804
52. Roe JW, Carding PN, Rhys-Evans PH, Newbold KL, Harrington KJ, Nutting CM (2012) Assessment and management of dysphagia in patients with head and neck cancer who receive radiotherapy in the United Kingdom - a web-based survey. Oral Oncol 48:343-348

53. Kao CY, Hu WY, Chiu TY, Chen CY (2013) Effects of the hospitalbased palliative care team on the care for cancer patients: an evaluation study. Int J Nurs Stud 51:226-235. doi:10.1016/j.ijnurstu.2013. 05.008

54. Güneri P, Cankaya H, Yavuzer A, Güneri EA, Erișen L, Ozkul D, El SN, Karakaya S, Arican A, Boyacioğlu H (2005) Primary oral cancer in a Turkish population sample: association with sociodemographic features, smoking, alcohol, diet and dentition. Oral Oncol 41:10051012

55. Fernandes LL, Torres SR, Garnica M, de Souza Gonçalves L, Junior AS, de Vasconcellos AC, Cavalcanti W, Maiolino A, de Barros Torres MC (2013) Oral status of patients submitted to autologous hematopoietic stem cell transplantation. Support Care Cancer 22:1521, PMID: 23975228

56. Lawrence M, Aleid W, McKechnie A (2013) Access to dental services for head and neck cancer patients. Br J Oral Maxillofac Surg 51: 404-407

57. Barasch A, Cunha-Cruz J, Curro F, Derouen T, Gilbert GH, Hujoel P, Safford MM, Vena DA, Voinea-Griffin AE, Wu H, CONDOR Collaborative Group (2013) Dental risk factors for osteonecrosis of the jaws: a CONDOR case-control study. Clin Oral Investig 17: $1839-1845$

58. Chang JS, Lo HI, Wong TY, Huang CC, Lee WT, Tsai ST, Chen KC, Yen CJ, Wu YH, Hsueh WT, Yang MW, Wu SY, Chang KY, Chang JY, Ou CY, Wang YH, Weng YL, Yang HC, Wang FT, Lin CL, Huang JS, Hsiao JR (2013) Investigating the association between oral hygiene and head and neck cancer. Oral Oncol. doi:10.1016/j. oraloncology. 2013.07.004

59. British Association of Head and Neck Oncologists. BAHNO standards (2009) Midhurst: BAHNO, 2009. (http:www.bahno.org.uk/ docs, Accessed on 23.10.2013)

60. Elad S, Thierer T, Bitan M, Shapira MY, Meyerowitz C (2008) A decision analysis: the dental management of patients prior to hematology cytotoxic therapy or hematopoietic stem cell transplantation. Oral Oncol 44:37-42

61. Jacobson JJ, Epstein JB, Eichmiller FC, Gibson TB, Carls GS, Vogtmann E, Wang S, Murphy B (2012) The cost burden of oral, oral pharyngeal, and salivary gland cancers in three groups: commercial insurance, Medicare, and Medicaid. Head Neck Oncol 4:15. doi: 10.1186/1758-3284-4-15, PubMed PMID: 22537712; PubMed Central PMCID: PMC3503554

62. Ghazali N, Kanatas A, Langley DJ, Scott B, Lowe D, Rogers SN (2011) Treatment referral before and after the introduction of the Liverpool patients concerns inventory $(\mathrm{PCI})$ into routine head and neck oncology outpatient clinics. Support Care Cancer 19:18791886

63. McGuire DB, Correa ME, Johnson J, Wienandts P (2006) The role of basic oral care and good clinical practice principles in the management of oral mucositis. Support Care Cancer 14:541-547

64. Alpöz E, Güneri P, Epstein JB, Cankaya H, Osmic D, Boyacıoğlu H (2013) Dental students' knowledge of characteristics and management of oral complications of cancer therapy. Support Care Cancer 21(10):2793-2798. doi:10.1007/s00520-013-1856-x, Epub 2013 Jun 1. PubMed PMID: 23729227

65. Eckardt A, Barth EL, Kokemueller H, Wegener G (2004) Recurrent carcinoma of the head and neck: treatment strategies and survival analysis in a 20-year period. Oral Oncol 40:427-432

66. Rethman MP, Carpenter W, Cohen EEW, Epstein J, Evans CA, Flaitz CM, Graham FJ, Hujoel PP, Kalmar JR, Koch WM, Lambert PM, Lingen MW, Oettmeier BW Jr, Patton LL, Perkins D, Reid BC, Sciubba JJ, Tomar SL, Wyatt AD Jr, Aravamudhan K, FrantsveHawley J, Cleveland JL, Meyer DM, for the American Dental 
Association Council on Scientific Affairs, Expert Panel on Screening for Oral Squamous Cell Carcinomas (2010) Evidence-based clinical recommendations regarding screening for oral squamous cell carcinomas. J Am Dent Assoc 141:509-520

67. Groome PA, Rohland SL, Hall SF, Irish J, Mackillop WJ, O'Sullivan B (2011) A population-based study of factors associated with early versus late stage oral cavity cancer diagnoses. Oral Oncol 47:642-647

68. Cankovic M, Ilic MP, Vuckovic N, Bokor-Bratic M (2013) The histological characteristics of clinically normal mucosa adjacent to oral cancer. J Cancer Res Ther 9:240-244

69. Jégu J, Binder-Foucard F, Borel C, Velten M (2013) Trends over three decades of the risk of second primary cancer among patients with head and neck cancer. Oral Oncol 49:9-14

70. Güneri P, Epstein J, Botto RW (2013) Breaking bad medical news in a dental care setting. J Am Dent Assoc 144:381-386

71. Corrigan DM, Walker MP, Liu Y, Mitchell TV (2013) Factors influencing patients seeking oral health care in the oncology dental support clinic at an urban university dental school setting. Spec Care Dentist. doi:10.1111/scd.12037
72. Epstein JB, Parker IR, Epstein MS, Stevenson-Moore P (2004) Cancer-related oral health care services and resources: a survey of oral and dental care in Canadian cancer centres. J Can Dent Assoc 70: 302-304

73. NHS Information Centre. National head and neck cancer audit 2010, sixth annual report. Leeds: Information Centre for Health and Social Care (2011) (http://www.hqip.org.uk/assets/NCAPOPLibrary/HeadNeck-Cancer-Audit-INTERACTIVE-2010-FINAL.pdf, accessed 23. 10. 2013).

74. Güneri P, Cankaya H, Kaya A, Boyacioğlu H (2008) Turkish dentists' knowledge of head and neck cancer therapy-related complications: implications for the future. Eur J Cancer Care (Engl) 17:84-92

75. Burke L, Croucher R (1996) Criteria of good dental practice generated by general dental practitioners and patients. Int Dent J 46:3-9

76. Kim MJ, Damiano PC, Hand J, Denehy GE, Cobb DS, Qian F (2012) Consumers' choice of dentists: how and why people choose dental school faculty members as their oral health care providers. J Dent Educ 76:695-704 